\title{
Prevalence of Migraine and its Relationship with Psychological Stress and Sleep Quality in Female University Students in Saudi Arabia
}

This article was published in the following Dove Press journal: Journal of Pain Research

\author{
Nazish Rafique (iD) ' \\ Lubna Ibrahim Al-Asoom (iD)' \\ Rabia Latif (D)' \\ Ahmed A Alsunni iD' \\ Ayad Mohammed Salem (iD) \\ Zainab Hameed Alkhalifa ${ }^{2}$ \\ Rana Mohammed Almaharfi ${ }^{2}$ \\ Rawan Sami Alramadan (iD ${ }^{2}$ \\ Zainab Falah Aldajani ${ }^{2}$ \\ Fatimah Abdulmuttalib Taher Alghadeer ${ }^{2}$ \\ Laila Abbas Albaghli iD ${ }^{2}$ \\ 'Department of Physiology, College of \\ Medicine, Imam Abdulrahman Bin Faisal \\ University, Dammam, Saudi Arabia; \\ ${ }^{2}$ College of Medicine, Imam Abdulrahman \\ Bin Faisal University Dammam, Dammam, \\ Saudi Arabia
}

Purpose: This study aimed to determine the prevalence of migraine in young female adults and to identify if a relationship exists between psychological stress or poor sleep quality and migraine.

Materials and Methods: This case control study was carried out at Imam Abdulrahman Bin Faisal University (IAU), Dammam, KSA from March 2019 to March 2020 on 1,990 female students (17- to 26-years-old). The study tools were Migraine Screening Questionnaire (MS-Q), International Headache Society (IHS) Criteria for Migraine, K10 Psychological Distress Instrument (K10) and Pittsburgh Sleep Quality Index (PSQI).

Results: A total of 103 out of 1,990 (5.17\%) participants were identified to have migraine. Migraineurs compared to controls had significantly higher average stress scores; felt more tired, nervous, restless, could not sit still, felt that everything was an effort, and nothing cheered them up ( $\mathrm{p}$ values; 0.008, 0.001, 0.02, 0.01, 0.004, 0.009, 0.02 respectively). Moreover, presence of migraine was significantly correlated with various stress parameters including "High K10 scores," "being tired," "being nervous," "restlessness," "inability to sit still," and "feeling that everything is an effort" (p values: 0.01, 0.002, 0.018, 0.01,0.005, $0.01,0.02)$. Regarding sleep quality and sleep parameters, no statistically significant difference was found between migraineurs and controls. No correlation was found between presence of migraine and poor sleep quality.

Conclusions: The results of this study indicate that $5.17 \%$ of young females (17- to 26 years-old) suffer from migraine. It also concludes that poor sleep quality is not correlated with migraine, whereas high stress scores are significantly correlated with migraine in young female adults.

Keywords: migraineurs, stress scores, sleep parameters, poor sleep quality

\section{Plain Language Summary}

Migraine is a type of primary headache which can be caused and/or aggravated by factors like psychological stress and poor sleep quality. We tried to determine the prevelance of migraine in young Saudi femlaes, and to identify if a relationship exists between psychological stress or poor sleep quality and migraine. This study was conducted on 1,990 young female university students (17- to 26-years-old). The results of the study showed that $5.17 \%$ participants had migraine. Migraineurs had significantly higher average stress scores; felt more tired, nervous, restless,could not sit still,felt that everything was an effort, and nothing cheered them up. Moreover,presence of migraine showed a strong positive relationship with various stress parameters including "High stress scores", "being tired", "being nervous","restlessness", "inability to sit still" and feeling that everything was an effort. These results
Correspondence: Ahmed A Alsunni Department of Physiology, College of Medicine, Imam Abdulrahman Bin Faisa University Dammam, P.O. Box 1982, Dammam 3144I, Saudi Arabia

Tel +966 I3 333। I88

Fax +96638578048

Email aalsunni@iau.edu.sa 
show that psychological stress may be a strong factor responsible for causing migraine. Regarding sleep quality and sleep parameters, no difference was found between migraineurs and controls. Moreover,no correlation was found between poor sleep quality and migraine, indicating that poor sleep quality may not have any role in causing migraine.

\section{Introduction}

Migraine is a frequently debilitating neurological condition which presents with moderate or severe headache, most of the time reported to be unilateral and throbbing in nature. It is often accompanied by sound sensitivity, light sensitivity, nausea, and vomiting. ${ }^{1}$ According to the Global Burden of diseases study in 2015, it was classified as the seventh cause of disability worldwide. Its estimated global prevalence is $16.6 \%$, being three times more common among females than males. In both sexes, peak prevalence occurs between the ages of 30 to 39 years. ${ }^{2}$ Migraine attacks can be triggered by many factors, including: emotional stress, insufficient or excessive sleep, odors, missing a meal, and menstruation. ${ }^{3}$ Individuals with migraine are at higher risk of experiencing chronic medical conditions, chronic pain conditions, ischemic stroke, sleep disruption, depression, anxiety, and increasing level of stress. ${ }^{4-6}$

Stress is one of the most prevalent factors, stated by almost $70 \%$ of migraineurs, to be a trigger of acute attacks. ${ }^{7}$ It is defined as a state of emotional strain in response to challenging life events that can be dangerous, demanding or threatening. ${ }^{8}$ Some studies found a positive correlation between psychological stress and migraine. ${ }^{9-12}$ Kelman et al indicated stress to be the most prevalent trigger of migraine attacks, as almost $80 \%$ of their participants reported a stressful event prior to their episode. ${ }^{13}$ Sauro and Becker suggested that stress is a predisposing factor for the development of a new onset migraine, as well as it being a triggering factor of an acute attack. ${ }^{14}$ However, few other researchers concluded that stress was not generally related to migraine attacks and increased stress of daily hassles did not have a strong effect on the attack of migraine. ${ }^{15-17}$ Likewise, a cross-sectional comparative study highlighted that stress does not trigger a migraine attack but makes patients more susceptible to other triggers. ${ }^{17,18}$

Sleep disruption is a common problem among migraineurs. Migraine attacks can be triggered by sleep disruption and improved with enough restful sleep. ${ }^{18-20}$ Various studies have shown that migraineurs have a higher prevalence of poor sleep quality compared to the normal population. ${ }^{18,21-23}$ In addition, healthy subjects with insomnia were found to be at higher risk of developing headaches 11 years later, and the relationship was stronger with chronic headaches such as migraine. $^{24}$ On the other hand, several studies have found no relationship between poor sleep quality and migraine. Fox and Davis reported no relationship between headache attacks and disturbed sleep. ${ }^{25}$ Furthermore, the study results of Bruni et al showed similar sleep parameters in both migraineurs and controls, however, sleep onset latency was longer in migraine subjects. $^{26}$

Inconclusive data about the role of psychological stress and poor sleep quality in causing migraine, led us to conduct this study. It aimed to determine the relationship of stress levels and sleep quality with migraine, by using the K10 Psychological Distress Instrument (K10) and Pittsburgh Sleep Quality Index (PSQI). In addition, we also aimed to find out the prevalence of migraine in the young female population (17- to 26-years-old) at Imam Abdulrahman Bin Faisal University, Dammam, Saudi Arabia.

\section{Materials and Methods}

This was a case control study conducted on 1,990 female students (17- to 26years-old), at the of College of Health Sciences, Imam Abdulrahman Bin Faisal University (IAU) Dammam, KSA.

The sample size calculation was done by the EpiTools epidemiological calculator (accessed at: http://epitools.aus vet.com.au/content.php?page=1ProportionandProportion), Given the estimated prevalence of migraine in young Saudi female university students (10.5\%) from a recent study in Makkah, ${ }^{27}$ with the desired precision $0.01(1 \%)$, confidence interval of 0.95 (95\%), and target population size as 2,500 , it came out to be 2,000 . But we were able to achieve a sample size of 1,990 .

Data was collected by convenience sampling technique. A ten minute briefing was given in various classes to explain the questionnaire and purpose of the study (Average number of students per class was 100). Ethical approval was given by Deanship of Scientific Research (DSR-IAU), (IRB -UGS-2019-01-325). All the participants provided informed consent. Participants under the age of 18 were approved by the ethics committee of DSRIAU to provide informed consent on their own behalf.

The research tool used was an online questionnaire, generated by using google forms.

The main tools of the questionnaire were: 


\section{Personal Data}

This part clustered information about the existence of any primary or secondary headache disorders (other than migraine). Information included any diagnosed sleep or respiratory disorders affecting quality of sleep, history of any mental or physical chronic illness, and history of medications.

\section{Screening the Students for Migraine}

The Migraine Screen Questionnaire (MS-Q) is a valid and reliable tool to detect the suspicion of migraine. ${ }^{28}$

All $(1,990)$ students completed the following online MS-Q. The students were directed to give the most accurate reply for the following questions, focusing on their symptoms during the last year.

1: Do you have frequent or intense headaches?

2: Do your headaches last for more than 4 hours?

3: Do you suffer from nausea when you have headache?

4: Does light or noise bother you when you have headache?

5: Does your headache limit any of your physical or intellectual activities?

Negative answer (NO) was designated a score of 0 , whereas a score of 1 was given for a positive answer of YES. A score of $\geq 4$ points raised a suspicion of migraine, while a $<4$ score indicated no migraine suspicion. ${ }^{28}$

Based upon the MS-Q, 153 out of 1,990 (7.6\%) students were suspected to have migraine.

These 153 students were further tested by using the online "International Headache Society Questionnaire" This questionnaire is a diagnostic criterion for migraine, established by the IHS, as below:

A. At least 5 attacks fulfilling criteria B-D (Symptoms occurring during the last year)

B. Headache attacks lasting 4-72 hours (untreated or unsuccessfully treated)

C. Headache has at least two of the following characteristics:

1. Unilateral location

2. Pulsating quality

3. Moderate or severe pain intensity

4. Aggravation by or causing avoidance of routine physical activity (eg walking or climbing stairs)

D. During headache at least one of the following:

(i) Nausea and/or vomiting

(ii) Photophobia and phonophobia
E. Headache not attributed to another disorder. ${ }^{29}$

Based upon IHS Questionnaire 110 out of 153 students were diagnosed to have migraine.

\section{Inclusion Criteria}

The inclusion criteria was, students diagnosed with migraine based on MS-Q and HIS.

\section{Exclusion Criteria}

The students with the following conditions and behaviors were excluded from the study:

Any diagnosed primary headache disorder (tension and cluster headaches), other than migraine.

Any diagnosed secondary headache disorders other than medication-overuse headache or unclassified headaches.

Any diagnosed disorder of sleep.

Any diagnosed chronic mental or physical illness, which affects sleep.

Using any form of prescription medication for the last 6 months.

Based upon the inclusion and exclusion criteria, 103 out of 110 students were selected as the migraine cases.

The controls were age and sex matched female university students. These controls were selected randomly from 1,880 migraine free subjects. In order to avoid the effects of various confounding factors, the same exclusion criteria were followed for both the cases and controls.

In order to screen for psychological stress and poor sleep quality, all the cases (103) and controls (103) filled the online K10 and the PSQI Questionnaire.

Various questionnaires are used to identify the stress levels and sleep quality. But we selected K10 and PSQI, as these have been found to be most cited, and most effective in terms of reliability and validity.

\section{KIO Psychological Distress Instrument for Screening the Students for Stress Levelss}

This is a questionnaire of 10 questions about the patient's experience of anxiety and depressive symptoms during the last month to measure stress levels.

The numbers are attached to the 10 responses of the subjects, which are summed up to get the final score that ranges from 10-50. Depending on these scores, the subjects are classified into 2 groups: high perceived stress (HPS Stress scores $\geq 24$ ) and low perceived stress (LPS Stress scores $<24){ }^{30}$ 


\section{Pittsburgh Sleep Quality Index (PSQI) for} Screening the Students for Sleep Quality

The PSQI has 19 self-rated items, focusing on the following 7 parameters: Subjective sleep quality, sleep latency, sleep duration, habitual sleep efficiency (the ratio of total sleep time to time in bed), sleep disturbances, the usage of sleep inducing medicines, and daytime dysfunction.

The value of each of the 7 sub-scores ranges from 0 to 3. These 7 sub-scores are added to form a global score ranging from 0 to 21 .

A score of $\geq 5$ means poor sleep quality, the bigger the score the poorer the sleep quality. ${ }^{31}$

\section{Data Analysis}

Statistical analysis was performed by SPSS Version 20 . The frequency and distribution of basic characteristics of migraine headache in migraineurs was calculated by using descriptive analyses. Stress parameters and sleep parameters were compared between the cases and the controls by an independent sample $t$-test. Association between stress parameters and migraine, and sleep parameters and migraine was found by Binary Logistic Regression analysis. In Binary Logistic Regression analysis, the presence or absence of migraine was taken as a dependent variable and all the stress and sleep variables as covariates. A Chisquare test was employed to find the association of clinical presentations of migraine participants with their perceived stress levels and sleep quality. All tests were two-sided with a significance level set at $P<0.05$.

\section{Results}

A total of 1,990 out of 2,500 (79.6\%) students completed and submitted the questionnaires. Based on inclusion exclusion criteria, 103 out of 1,990 (5.27\%) participants were identified to have migraine. The mean age of the subjects was $21.07( \pm 3.32)$ years.

Table 1, shows the basic characteristics of migraine headache in migraineurs. As seen in the table, $98 \%$ of the cases reported having frequent or intense headaches. These headaches lasted for more than 4 hours in $97 \%$ of the subjects. Nausea was experienced by $65.7 \%$ of subjects; light or noise was bothersome for $90 \%$; and $88.7 \%$ mentioned that headache limited their physical or intellectual activates.

No statistically significant difference was observed between the clinical presentations of migraine with HPS and LPS. It indicates that stress scores do not affect the clinical presentations in migraineurs including: frequency or intensity of headaches, duration of headache, association with nausea and vomiting, association with photophobia or photophobia, limiting physical or mental abilities and pulsating in quality.

Number and percentages of migraineurs with HPS and LPS was $49(47.6 \%)$ and 54 (52.4\%) respectively. Meanwhile, the number and percentages of controls falling in the categories of HPS and LPS was 32 (31.1\%) and 71 (68.9\%) respectively. These numbers indicate a higher prevalence of HPS in migraineurs compared to controls.

Table 2 shows the comparison of average stress scores between migraineurs and controls. The cases as compared to controls had significantly higher average stress scores: felt more tired, nervous, restless, could not sit still, felt that everything was an effort, and nothing cheered them up ( $p$ values: $0.008,0.001,0.02,0.01,0.004,0.009,0.02$ respectively).

A significant positive correlation was seen between presence of migraine and various stress parameters including "High K10 scores," "being tired," "being nervous," "restlessness," "inability to sit still," and "feeling that everything is an effort" ( $p$ values: 0.01, 0.002, 0.018, $0.01,0.005,0.01,0.02$ ) Table 3 .

Regarding sleep and migraine, the number and percentages of migraineurs with poor sleep quality (PSQI $\geq 5$ ) and normal sleep quality (PSQI $<5)$ were $85(82.5 \%)$ and $18(17.5 \%)$, respectively. Additionally, the number and percentages of controls falling in the categories of poor and normal sleep were $87(84.5 \%)$ and $16(15.5 \%)$ respectively, thereby indicating almost the same prevalence of poor sleep quality in both the cases and controls.

No statistically significant difference was observed between the clinical presentations of migraine with poor and normal sleep quality. It indicates that sleep quality does not affect the clinical presentations in migraineurs including: frequency or intensity of headaches, duration of headache, association with nausea and vomiting, association with photophobia or photophobia, limiting physical or mental abilities and pulsating in quality.

Regarding sleep quality and sleep parameters, no statistically significant difference was seen between migraineurs and controls, as seen in Table 4. Moreover, binary logistic regression analysis indicated no correlation between migraine and poor sleep parameters scores, as seen in Table 5. 


\section{Discussion}

The present study showed that the overall prevalence of migraine is $5.17 \%$ among health science female students in IAU. The prevalence of migraine is variable worldwide. According to a systematic review and meta-analysis of multiple community-based studies, the pooled crude migraine prevalence was $11.6 \%$. Migraine prevalence was $10.4 \%$ in Africa, $10.1 \%$ in Asia, $11.4 \%$ in Europe and $16.4 \%$ in Central and South America. It has been observed that migraine occurs twice as much in females as compared to males, $13.8 \%$ and 6.9 receptively. ${ }^{32}$ Comparatively, the lower prevalence of migraine in our study can be explained by the young age of our participants (17- to 26-years-old) and most reviews focus on diagnosed patients between 30 and 40 years, when migraine tends to peak. ${ }^{2,33,34}$

Our results are consistent with the other studies conducted on male and female medical students (with a mean age of 23 years) in Jazan, Iran and Athens, where the prevalence of migraine was $5.0 \%$ and $7.42 .4 \%$, respectively. ${ }^{35-37}$ On the other hand, a study conducted among male and female medical student at Kuwait University reported a prevalence of $25.7 \% .^{38}$ Our prevalence was also lower when compared with studies conducted with females subjects only. Garah et al reported migraine prevalence of $61.8 \%$ among female students in Taibah university. ${ }^{39}$ Other studies reported migraine prevalence of $68.4 \%$ at Taif University and $10 \%$ in Umm AlQura University in the female subjects. ${ }^{40,41 .}$ These differences can be attributed to variations in study designs, methodology and types of self-reporting questioners that were used. Other contributing factors might include different racial, environmental, climatic factors, socioeconomic status or nutritional habits.

An important finding of this study was that migraineurs had higher stress levels in comparison to controls. Moon et al also used a PSS questionnaire and revealed that the level of stress was significantly higher in their chronic migraine patients than in controls., ${ }^{9}$ Wacogne et al also found that stress and anxiety disorders were more common in the migraineurs group when compared with the control group. $^{12}$

Our findings suggest a strong positive correlation between stress and migraine. But, due to the cross sectional study design, we were not able to find out a bidirectional and longitudinal relation between stress and migraine. Although, various other studies have proposed that stress does not only
Table I Characteristics of Migraine Headache in Migraineurs

\begin{tabular}{|l|l|l|}
\hline $\begin{array}{l}\text { Characteristics of } \\
\text { Migraine Headache }\end{array}$ & $\begin{array}{l}\text { Yes } \\
{[\text { Number of }} \\
\text { Students (\%)] }\end{array}$ & $\begin{array}{l}\text { No } \\
{[\text { Number of }} \\
\text { Students (\%)] }\end{array}$ \\
\hline $\begin{array}{l}\text { Do you have frequent or } \\
\text { intense headache? }\end{array}$ & $101(98 \%)$ & $2(2 \%)$ \\
\hline $\begin{array}{l}\text { Headache lasts for more than } \\
\text { 4 hours? }\end{array}$ & $100(97 \%)$ & $3(3 \%)$ \\
\hline Nausea during headache? & $68(65.7 \%)$ & $35(34.3 \%)$ \\
\hline $\begin{array}{l}\text { Light or noise is bothersome } \\
\text { during headache? }\end{array}$ & $93(90.14 \%)$ & $10(9.86 \%)$ \\
\hline $\begin{array}{l}\text { Headache limits the physical } \\
\text { or intellectual activates }\end{array}$ & $91(88.7 \%)$ & $12(11.3 \%)$ \\
\hline Unilateral location & $65(63.1 \%)$ & $38(36.9 \%)$ \\
\hline Pulsating quality & $85(82.5 \%)$ & $18(17.5 \%)$ \\
\hline $\begin{array}{l}\text { Headache aggravated by } \\
\text { routine physical activity }\end{array}$ & $69(67 \%)$ & $34(33 \%)$ \\
\hline
\end{tabular}

trigger an acute attack, but can also work as a predisposing factor to have migraine. ${ }^{14}$ Similarly, another study assessed the relation between stress and migraine longitudinally and bidirectionally, suggesting that stress is a risk factor for migraine. ${ }^{42}$ In addition, patients suffering from primary

Table 2 Comparison of Stress Scores Between Migraineurs and Controls

\begin{tabular}{|l|l|l|l|}
\hline Stress Parameters & $\begin{array}{l}\text { Migraineurs } \\
\text { (Mean } \pm \text { SD) }\end{array}$ & $\begin{array}{l}\text { Control } \\
\text { (Mean } \pm \text { SD) }\end{array}$ & P value \\
\hline Age & $21.07 \pm 3.32$ & $22.14 \pm 4.08$ & $0.04^{*}$ \\
\hline KI0 scores & $24.40 \pm 7.67$ & $21.56 \pm 7.57$ & $0.008^{*}$ \\
\hline Tired & $2.99 \pm 0.79$ & $2.59 \pm 0.98$ & $0.00 I^{*}$ \\
\hline Nervous & $3.05 \pm 0.90$ & $2.73 \pm 0.99$ & $0.02^{*}$ \\
\hline Cannot calm down & $2.03 \pm 0.99$ & $1.77 \pm 0.92$ & 0.05 \\
\hline Hopeless & $2.26 \pm 1.17$ & $2.20 \pm 1.12$ & 0.72 \\
\hline Restless or fidgety & $2.55 \pm 1.03$ & $2.19 \pm 1.02$ & $0.01 *$ \\
\hline Cannot sit still & $2.07 \pm 1.01$ & $1.68 \pm 0.92$ & $0.004^{*}$ \\
\hline Depressed & $2.54 \pm 1.22$ & $2.40 \pm 1.07$ & 0.36 \\
\hline Everything an effort & $2.62 \pm 0.91$ & $2.26 \pm 1.03$ & $0.009^{*}$ \\
\hline Nothing cheer up & $2.30 \pm 1.18$ & $1.92 \pm 1.03$ & $0.02^{*}$ \\
\hline Worthless & $1.98 \pm 1.26$ & $1.82 \pm 1.04$ & 0.30 \\
\hline
\end{tabular}

Note: ${ }^{*}$-value $<0.05$ is statistically significant. 
Table 3 Correlation of Stress Variables with the Presence and Absence of Migraine

\begin{tabular}{|l|l|l|l|l|}
\hline \multirow{2}{*}{$\begin{array}{l}\text { Ptress } \\
\text { Parameters }\end{array}$} & P value & $\begin{array}{l}\text { Odds } \\
\text { Ratio }\end{array}$ & \multicolumn{2}{|l|}{$\begin{array}{l}\text { 95\% CI for the } \\
\text { OR }\end{array}$} \\
\cline { 3 - 5 } & & & Lower & Upper \\
\hline KI0 score & $0.01 *$ & 1.05 & 1.01 & 1.09 \\
\hline Tired & $0.002^{*}$ & 1.67 & 1.21 & 2.31 \\
\hline Nervous & $0.018^{*}$ & 1.43 & 1.065 & 1.924 \\
\hline Cannot calm down & 0.05 & 1.33 & 0.997 & 1.785 \\
\hline Hopeless & 0.71 & 1.05 & 0.823 & 1.328 \\
\hline Restless or fidgety & $0.01 *$ & 1.41 & 1.073 & 1.856 \\
\hline Cannot sit still & $0.005^{*}$ & 1.52 & 1.132 & 2.037 \\
\hline Depressed & 0.36 & 1.12 & 0.880 & 1.421 \\
\hline Everything an effort & $0.01 *$ & 1.48 & 1.097 & 1.984 \\
\hline Nothing cheer up & $0.02^{*}$ & 1.37 & 1.059 & 1.763 \\
\hline Worthless & 0.31 & 1.13 & 0.892 & 1.440 \\
\hline
\end{tabular}

Note: *p-value $<0.05$ is statistically significant.

chronic headache, including tension type headache and migraine, had reported a significant increase in stressful life events in the year prior to the onset of headache. ${ }^{43}$

These results could be explained by the fact that hypothalamic-pituitary-adrenocortical axis is stimulated in response to stress, resulting in the activation of corticotrophin releasing hormone, thus triggering changes in the serotonin receptors. This results in degranulation of the cells located near the trigeminal nerve endings, leading to release of vasoactive and inflammatory mediators causing migraine. $^{44-46}$

In opposition to our findings, Yalinay et al documented no difference in the stress scores between migraineurs and controls ( 42.5 vs. $34.1 \%$ ). This might be due to the small sample size used in their study ( 87 migraines and 41 controls). ${ }^{47}$ Our results also contradict the findings of Lipton et al, who reported that decrease in stress levels precipitate an increase of migraine attacks. ${ }^{16}$ Moreover Hashizume et al observed that the increased stress of daily hassles did not have a strong effect on the intensity of migraine. ${ }^{48}$ These contradictory results can be explained by the different subjects' age, the sample size or the use of different stress scales.

In this study, we also tried to explore the relationship between poor sleep quality and migraine. However, no
Table 4 Comparison of Sleep Quality and Different Sleep Parameters Between Migraineurs and Controls

\begin{tabular}{|l|l|l|l|}
\hline Sleep Parameters & $\begin{array}{l}\text { Migraineurs } \\
\text { (Mean } \pm \\
\text { SD) }\end{array}$ & $\begin{array}{l}\text { Controls } \\
\text { (Mean } \pm \\
\text { SD) }\end{array}$ & P-values \\
\hline PSQI score & $7.09 \pm 2.82$ & $6.95 \pm 2.45$ & 0.712 \\
\hline $\begin{array}{l}\text { Subjective sleep quality } \\
\text { (Component I scores) }\end{array}$ & $1.26 \pm 0.67$ & $1.11 \pm 0.75$ & 0.120 \\
\hline $\begin{array}{l}\text { Sleep latency (PSQI2 in } \\
\text { minutes) }\end{array}$ & $33.97 \pm 29.37$ & $\begin{array}{l}29.52 \\
\pm 27.64\end{array}$ & 0.264 \\
\hline $\begin{array}{l}\text { Sleep duration in hours } \\
\text { (PSQI4) }\end{array}$ & $6.62 \pm 1.89$ & $6.57 \pm 2.11$ & 0.862 \\
\hline $\begin{array}{l}\text { Habitual sleep efficiency } \\
\text { (\%) }\end{array}$ & $84.98 \pm 15.25$ & $\begin{array}{l}84.82 \\
\pm 15.44\end{array}$ & 0.939 \\
\hline $\begin{array}{l}\text { Sleep disturbance } \\
\text { (Sumof5b-5j)) }\end{array}$ & $6.62 \pm 3.73$ & $6.83 \pm 4.14$ & 0.711 \\
\hline $\begin{array}{l}\text { Day time dysfunction } \\
\text { (adding scores of 8-9) }\end{array}$ & $1.83 \pm 1.65$ & $1.63 \pm 1.35$ & 0.332 \\
\hline
\end{tabular}

significant difference was found between the migraineurs and controls in term of sleep quality and different sleep parameters. Our findings were consistent with the results of Fox and David, who showed no exact relationship between migraine headaches and disturbed sleep. $^{25}$

Table 5 Correlation of Sleep Quality and Different Sleep Parameters with Migraine

\begin{tabular}{|l|l|l|l|l|}
\hline Parameters & P value & $\begin{array}{l}\text { Odds } \\
\text { Ratios }\end{array}$ & \multicolumn{2}{|l|}{$\begin{array}{l}\text { 95\% } \\
\text { Confidence } \\
\text { Interval }\end{array}$} \\
\cline { 3 - 5 } & & & Lower & Upper \\
\hline PSQI score & 0.71 & 1.02 & 0.919 & 1.132 \\
\hline $\begin{array}{l}\text { Subjective sleep } \\
\text { quality }\end{array}$ & 0.12 & 1.36 & 0.922 & 2.011 \\
\hline Sleep latency & 0.27 & 1.01 & 0.996 & 1.016 \\
\hline Sleep duration & 0.86 & 1.01 & 0.883 & 1.161 \\
\hline $\begin{array}{l}\text { Habitual sleep } \\
\text { efficiency }\end{array}$ & 0.94 & 1.001 & 0.983 & 1.019 \\
\hline Sleep disturbance & 0.71 & 0.99 & 0.920 & 1.058 \\
\hline Day time dysfunction & 0.33 & 1.10 & 0.912 & 1.316 \\
\hline Bed time & 0.65 & 1.43 & 0.834 & 1.062 \\
\hline Wake up time & 0.52 & 1.79 & 0.929 & 1.123 \\
\hline
\end{tabular}


Moreover Bruni et al monitored the objective sleep quality of migraineurs children via actigraphs and found no difference from controls. ${ }^{26}$ In contrast to our results, a huge data shows a positive association between poor sleep quality and migraine. ${ }^{18-23}$ Gori et al and Kim et al concluded that poor sleep quality was considerably greater in migraine subjects when compared to controls. $^{49,50}$ However, most of these studies are not case control studies, or have not used matched cases and controls in term of age, sex, and sleeping habits. In Contrast, in the present study we have used $100 \%$ matched cases and controls. Our subjects were not only age and sex matched but also had nearly similar sleeping habits. Another possible explanation could be that the previous mentioned studies were conducted on older population whereas our study was conducted on a younger population. Because sleep problems are more prevalent in older age group, poor sleep quality in this age group may be a stimulating factor for developing migraine. But we recommend further retrospective and bidirectional studies with large sample size to explore this discrepancy.

The strength of this study is the controlled study design, large sample size and similarity of cases and controls regarding biographic data. Regarding study limitations, sleep quality and sleep parameters were not evaluated by objective assessment tool, such as polysomnography (PSG), because it is difficult to perform PSG for all participants, but instead, we have used PSQI questionnaires, which show good agreement with PSG. Moreover, the exclusion criteria including the diagnosis of any primary or secondary headache disorder (other than migraine), sleep disorder and chronic physical or mental illness were based on self reporting by the students.

\section{Conclusion}

The results of this study conclude that:

$5.17 \%$ of young Saudi females students (17- to 26years-old) suffer from migraine.

Stress scores are significantly higher in migraineurs compared to controls.

There is strong positive correlation between migraine and stress parameters.

Poor sleep quality and poor sleep parameters scores are not correlated with migraine.

\section{Acknowledgments}

Authors fully acknowledge the support and ethical approval given by the Deanship of Scientific Research (DSR-IAU), (IRB-UGS-2019-01-325), Imam Abdulrahman Bin Faisal University (IAU), Dammam, KSA.

\section{Disclosure}

The authors report no conflicts of interest in this work.

\section{References}

1. Headache Classification Committee of the International Headache Society (IHS). The international classification of headache disorders, 3rd edition (beta version). Cephalalgia. 2013;33:629-808. doi: $10.1177 / 0333102413485658$

2. GBD. 2015 disease and injury incidence and prevalence collaborators. Global, regional, and national incidence, prevalence, and years lived with disability for 310 diseases and injuries. A systematic analysis for the global burden of disease study. Lancet. 2016;388:1545-1602. doi:10.1016/S0140-6736(16)31678-6

3. Andress RD, King W, Rothrock J. An analysis of migraine triggers in a clinic-based population. J Head Face Pain. 2010;50:1366-1370. doi:10.1111/j.1526-4610.2010.01753.x

4. Saunders K, Merikangas K, Low N, et al. Impact of comorbidity on headache-related disability. Neurology. 2008;70:538-574. doi:10.1212/01.wnl.0000297192.84581.21

5. Schurks M, Rist P, Bigel M, et al. Migraine and cardiovascular disease: systematic review and meta-analysis. BMJ. 2009;339:3914-3920. doi:10.1136/bmj.b3914

6. Buse D, Silberstein S, Manack A, et al. Psychiatric comorbidities of episodic and chronic migraine. J Neurol. 2013;260(8):1960-1969. doi:10.1007/s00415-012-6725-x

7. Theeler BJ, Kenney K, Prokhorenko OA, Fideli US, Campbell W, Erickson JC. Headache triggers in the US military. Headache. 2010;50:790-794.

8. Dodick DW, Silberstein SD. Migraine. Third edition. New York: Oxford university press; 2016:124.

9. Moon HJ, Seo JG, Park SP. Perceived stress in patients with migraine: a case-control study. $J$ Headache Pain. 2017;18:73-79.

10. Holm J, Lokken C, Myers T. Migraine and stress: a daily examination of temporal relationships in women migraineurs. Headache $J$. 1997;37:553-558. doi:10.1046/j.1526-4610.1997.3709553.x

11. Raggi A, Giovannetti A, Quintas R, et al. A systematic review of the psychosocial difficulties relevant to patients with migraine. J Headache Pain. 2012;13:595-606. doi:10.1007/s10194-012-0482-1

12. Wacogne C, Lacoste J, Guillibert E, et al. Stress, anxiety, depression and migraine. SAGE J. 2003;23:451-455.

13. Kelman L. The triggers or precipitants of the acute migraine attack. Cephalalgia. 2007;1(27):394 402. doi:10.1111/j.1468-2982.2007.01303.x

14. Sauro KM, Becker WJ. The stress and migraine interaction. Headache. 2009;49:1378-1386. doi:10.1111/j.1526-4610.2009.01486.x

15. Park JW, Chu MK, Kim JM, et al. Analysis of trigger factors in episodic migraineurs using a smartphone headache diary applications. PLoS One. 2016;22(11):341-356.

16. Lipton RB, Buse DC, Hall CB, et al. Reduction in perceived stress as a migraine trigger: testing the "let-down headache" hypothesis. Am Acad Neurol. 2014;82:1395-1401. doi:10.1212/WNL.0000000000000332

17. Kelman L, Rains JC. Headache and sleep: examination of sleep patterns and complaints in a large clinical sample of migraineurs. $J$ Head Face Pain. 2005;45:904-910. doi:10.1111/j.1526-4610.2005.05159.x

18. Parshar R, Bhalla P, Rai N, et al. Migraine: is it related to hormonal disturbances or stress? Int J Womens Health. 2014;6:921-925. doi:10.2147/IJWH.S62922 
19. Alberti A. Headache and sleep. Sleep Med Rev. 2006;10:431-437. doi:10.1016/j.smrv.2006.03.003

20. Sahota P. Morning headaches in patients with sleep disorders. Sleep Med. 2003;4:377-381. doi:10.1016/S1389-9457(03)00103-5

21. Seidel S, Hartl T, Weber M, et al. Quality of sleep, fatigue and daytime sleepiness in migraine - a controlled study. Cephalalgia. 2009;29:662-669. doi:10.1111/j.1468-2982.2008.01784.x

22. Zhu Z, Fan X, Li X, et al. Prevalence and predictive factors for poor sleep quality among migraineurs in a tertiary hospital headache clinic. Acta Neurol Belg. 2013;113:23229. doi:10.1007/s13760-0120159-1

23. Rasmussen BK. Migraine and tension-type headache in a general population: precipitating factors, female hormones, sleep pattern and relation to lifestyle. Pain. 1993;53:65-72. doi:10.1016/03043959(93)90057-V

24. Odegard SS, Engstrom M T, et al. The long-term effect of insomnia on primary headaches: a prospective population-based cohort study (HUNT-2 and HUNT-3). $j$ Head Face pain. 2011;51:570-580. doi: $10.1111 /$ j. $1526-4610.2011 .01859 . x$

25. Fox A, Davis R. Migraine chronobiology. Headache. J Head Face Pain. 1998;38:436-441. doi:10.1046/j.1526-4610.1998.3806436.x

26. Bruni O, Russo P, Violani C, Guidetti V. Sleep and migraine: an actigraphic study. Cephalalgia. 2004;24:134-139. doi:10.1111/ j.1468-2982.2004.00657.x

27. Primary headache characters and coping strategies among medical students of Umm Al-Qura University in the Western Region of Saudi Arabia. Neurosciences. 2018;23(308313).

28. Lainez M, Domínguez M, Rejas J, et al. Development and validation of the Migraine Screen Questionnaire (MS-Q). Headache. 2005;45:1328-1338. doi:10.1111/j.1526-4610.2005.00265.x

29. Olesen J. The international classification of headache disorders, 2nd edn (ICDH-II). J Neurol Neurosurg Psychiatry. 2004;75:808-811. doi:10.1136/jnnp.2003.031286

30. Kessler RC, Andrews G, Colpe LJ, et al. Short screening scales to monitor population prevalences and trends in non-specific psychological distress. Psychol Med. 2002;32:959-976. doi:10.1017/ S0033291702006074

31. Buysse D, Reynolds C, Monk T, et al. The Pittsburgh sleep quality index: A new instrument for psychiatric practice and research. Psychiatry Res. 1989;28:193-213. doi:10.1016/0165-1781(89)90047-4

32. Woldeamanuel Y, Cowan R. Global migraine epidemiology: systematic review and meta-analysis of 302 community-based studies involving 6,216,995 participants. Ann Global Health. 2016;82:570-575. doi:10.1016/j.aogh.2016.04.530

33. Pavlovic J. Evaluation and management of migraine in midlife women. Menopause. 2018;25(8):927-929. doi:10.1097/GME.00000 00000001104

34. Victor T, Hu X, Campbell J, et al. Migraine prevalence by age and sex in the United States: a life-span study. Cephalalgia. 2010;30:1065-1072. doi:10.1177/0333102409355601

35. Akour A, Shabi W, Ageeli A. Prevalence of migraine among medical students in Jazan University and its impact on their daily activities. Egyptian J Hospital Med. 2018;70:872-876. doi:10.12816/0043998
36. Shahrakai MR, Mirshekari H, Ghanbari AT, et al. Prevalence of migraine among medical students in Zahedan faculty of medicine (Southeast of Iran). Basic Clin Neurosci. 2011;15:20-25.

37. Mitsikostas DD, Gatzonis S, Thomas A, et al. An epidemiological study of headaches among medical students in athens. $j$ Head Face Pain. 1996;36:1366-1370. doi:10.1046/j.1526-4610.1996.3609561.x

38. Hashel JY, Ahmed SF, Alroughani R, et al. Migraine among medical students in Kuwait University. J Headache Pain. 2014;15:26-30. doi:10.1186/1129-2377-15-26

39. Jabry NT, Abduljabbar Z, Maqsud AN, et al. Prevalence and risk factors of tension headache among 3rd year female medical students at Taibah University in Saudi Arabia. Int J Academic Sci Res. 2015;3:46-53.

40. Desouky DE, Zaid HA, Taha AA, et al. Migraine, tension-type headache, and depression among Saudi female students in Taif University. $J$ Egypt Public Health Assoc. 2019;94:7-11. doi:10.1186/s42506019-0008-7

41. Khairoalsindi OA, Saber WK, Althubaiti NA, et al. Primary headache characters and coping strategies among medical students of Umm Al-Qura University in the Western Region of Saudi Arabia. Neurosciences. 2018;23:308-313319. doi:10.17712/ nsj.2018.4.20180256

42. Martin PR, Forsyth MR, Reece J. Cognitive-behavioral therapy versus temporal pulse amplitude biofeedback training for recurrent headache. Behav Ther. 2007;38:350-363. doi:10.1016/j. beth.2006.10.004

43. Benedittis G, Lorenzetti A, Pieri A. The role of stressful life events in the onset of chronic primary headache. Pain. 1990;40:65-75. doi:10.1016/0304-3959(90)91052-K

44. Strassman AM, Raymond SA, Burstein R. Sensitization of meningeal sensory neurons and the origin of headaches. Nature. 1996;384:560-564. doi:10.1038/384560a0

45. Theoharides TC, Spanos C, Pang X, et al. Stress-induced intracranial mast cell degranulation: a corticotropin-releasing hormone-mediated effect. Endocrinology. 1995;136:5745-5750. doi:10.1210/ endo.136.12.7588332

46. Olness K, Hall H, Rozniecki JJ, et al. Mast cell activation in children with migraine before and after training in self-regulation. Headache. 1999;39:101-107. doi:10.1046/j.1526-4610.1999.3902101.x

47. Yalinay DP, Yavuz BG, Aydinar EI. The relationships between migraine, depression, anxiety, stress, and sleep disturbances. Acta Neurol Belg. 2015;115:117-122. doi:10.1007/s13760-014-0312-0

48. Hashizume M, Yamada U, Sato A, et al. Stress and psychological factors before a migraine attack: a time-based analysis. Biopsychosoc. 2008;2:14-18. doi:10.1186/1751-0759-2-14

49. Gori S, Morelli N, Maestri M, et al. Sleep quality, chronotypes and preferential timing of attacks in migraine without aura. $J$ Headache Pain. 2005;6(4):258-260. doi:10.1007/s10194-005-0201-2

50. Kim J, Cho S, Kim W, et al. Insufficient sleep is prevalent among migraineurs: a population-based study. Headache Pain. 2017;18 (1):50-56. doi:10.1186/s10194-017-0756-8
Journal of Pain Research

\section{Publish your work in this journal}

The Journal of Pain Research is an international, peer reviewed, open access, online journal that welcomes laboratory and clinical findings in the fields of pain research and the prevention and management of pain. Original research, reviews, symposium reports, hypothesis formation and commentaries are all considered for publication. The manuscript management system is completely online and includes a very quick and fair peer-review system, which is all easy to use. Visit http:// www.dovepress.com/testimonials.php to read real quotes from published authors. 